\title{
Zoneamento de riscos de incêndios florestais em regiões hot spot de focos de calor no estado do Acre
}

\author{
Fabrício Assis LEAL ${ }^{1 *}$, Francisca Fabricia Bezerra de SOUZA, Glória da Silva Almeida LEAL \\ ${ }^{1}$ Universidade Federal do Acre, Cruzeiro do Sul, AC, Brasil. \\ E-mail: fabricioassisleall@gmail.com
}

\begin{abstract}
Recebido em maio/2018; Aceito em dezembro/2018.
RESUMO: O presente estudo teve como objetivo realizar um zoneamento de riscos de incêndios florestais para a região Hot Spot de focos de calor no estado do Acre em 2016. Para identificar os municípios que fariam parte desta abordagem foi realizada análise de agrupamento Hot Spot. Após seleção dos municípios foram consideradas as seguintes variáveis para o zoneamento: declividade, orientação das encostas, altitude, rede viária, zonas urbanas, núcleos populacionais e uso do solo. Essas variáveis foram integradas por uma somatória em que todas elas receberam o mesmo peso. Os riscos foram classificados em cinco níveis, sendo: baixo, moderado, alto, muito alto e extremo. Ao todo, quatro municípios foram considerados Hot Spot e tiveram seu zoneamento de risco realizado. Entre as classes destacaram-se as de riscos Alto (24\%), Moderado (25,5\%) e Baixo (23,9\%). Por outro lado, os riscos mais preocupantes tiveram porcentagem modestas, em relação as outras classes de risco, sendo risco Muito Alto com 14,1\% da área total e risco Extremo com apenas 12,5\% da área. Os resultados qualificados e quantificados do zoneamento de risco de incêndios foram de grande relevância, pois mostraram aquelas classes de riscos mais preocupantes por terem maior abrangência e maior alcance nas regiões Hot Spot de focos de calor. Palavras-chave: análise espacial, geoprocessamento, mapeamento geoespacial.
\end{abstract}

\section{Mapping of forestry fire risks in the hot spot region of heat focus, acre}

\begin{abstract}
The objective of this study was to carry out a risk zoning of forest fires in a region. To reach the outbreaks of heat and state of Acre in 2016. After the distribution of the answers, the altitude varied for zoning: slope, slope orientation, altitude, road network, urban areas, population centers and land use. These variables were integrated by a summation in all the same ones that received the weight. The touches were classified in low levels, being: low, moderate, high, very high and extreme. In all, four nations were Hot Spot stocks and had their risk zoning done. Among the classes, the highlights were High (24\%), Moderate (25.5\%) and Low (23.9\%). On the other hand, the most worrisome risks were modest rates, in relation to the other risk classes, and the risk of capital loss was greater than $14.1 \%$ of the total area and Extreme risk with only $12.5 \%$ of the area. The indexes and quantification of fuel risk zoning were of great relevance, since they were found as more worrying risk classes due to a greater and greater extent in the regions.
\end{abstract}

Keywords: geospatial analysis, geoprocessing, geospatial mapping.

\section{INTRODUÇÃO}

O fogo começou a ser utilizado no manejo de ambientes agrícolas e pastoris por ser mais viável economicamente e, por isso, está inserido na cultura humana há milhares de anos (MIRANDA, 2007). Por meio de atividades bem planejadas e cuidadosamente pensadas, o fogo oportuniza vários benefícios ao homem e ao ambiente, entretanto, na maioria das vezes, o fogo é utilizado sem levar em conta nenhum planejamento estratégico sequer, podendo acarretar na perda de seu controle e, por vezes, resultar em danos ecológicos e perdas biológicas imensuráveis (SOARES, 1985).

Não é de hoje que a preocupação com os incêndios florestais, que significa o fogo fora de controle, tem tomado grandes proporções. Bem mais do que prejuízos financeiros, os incêndios florestais trazem grandes ameaças a biodiversidade e aos ecossistemas (SOUZA, 2008). Diante disso, vem sendo tentado, de muitas formas, minimizar os efeitos negativos que o fogo, fora de controle, deixa como consequência na paisagem e na fauna.

Dentre algumas formas de minimizar essas consequências cita-se: o monitoramento utilizando a vigilância terrestre por postos de observação, torres e até patrulhamento aéreo. Entre as formas mais contemporâneas, de uso recorrente e de grande efetividade para esse fim estão os zoneamentos de risco de incêndios florestais, por meio de ferramentas geotecnológicas (BATISTA, 2004).

Segundo Letti (2012), o zoneamento é uma ferramenta de planejamento que realiza a delimitação de áreas categorizadas, pois mapeia o espaço desejado e indica regiões mais propensas a ocorrência de determinados acontecimentos, levando em consideração variáveis que estão relacionadas à ocorrência de incêndios.

Segundo Tetto et al. (2012), realizar análise minuciosa do maior número possível de variáveis que possam explicar e que envolvem incêndios florestais é de fundamental importância, pois quanto mais variáveis explicativas são inseridas no zoneamento, mais fidedignas são as estimativas dos riscos.

De acordo com Torres et al. (2017), as ferramentas computacionais geotecnológicas facilitam bastante os monitoramentos espaciais de previsão e combate a incêndios. E com auxílio do Sistema de Informações Geográficas (SIG) torna possível detectar os locais de maior risco de ocorrência, 
pois informa a distribuição espacial dos incêndios florestais, como consequência melhora as estratégias de prevenção.

Para Ribeiro et al. (2008), realizar o mapeamento ou zoneamento de riscos de incêndios florestais é parte essencial no planejamento racional dos recursos destinados à prevenção. Com o zoneamento de riscos de incêndios é possível proteger áreas propensas a riscos através de planejamento direcionado, pois o zoneamento proporciona uma visão espacial da área com base em informações geoespacializadas.

Diante do exposto, o objetivo deste trabalho foi elaborar um zoneamento dos riscos de incêndios florestais para a região Hot Spot de focos de calor no Acre, para o ano de 2016.

\section{MATERIAL E MÉTODOS}

\subsection{Localização da área de estudo}

O presente estudo foi realizado no estado do Acre, que está localizado na região norte do país (Figura 1), sendo que o mesmo possui área total de $152.581 \mathrm{~km}^{2}$, divididos em 22 municípios. O relevo da região é caracterizado por depressão na maior parte do território e planície estreita ao norte. De acordo com a classificação realizada por Alvares et al. (2013), o clima é equatorial. Está situado no extremo sudoeste da Amazônia brasileira, entre as latitudes de $07^{\circ} 07^{\prime} \mathrm{S}$ e $11^{\circ} 08^{\prime} \mathrm{S}$, e as longitudes de $66^{\circ} 30^{\prime} \mathrm{W}$ e $74^{\circ} \mathrm{W}$ (ACRE, 2010).

Devido aos altos valores de energia solar recebidos na superfície, a temperatura do ar demonstra pequena variação durante o ano, em que as médias anuais apresentam temperaturas bastante elevadas na região central equatorial, com médias que ultrapassam os $26^{\circ} \mathrm{C} / 28^{\circ} \mathrm{C}$ (COSTA et al., 2012).

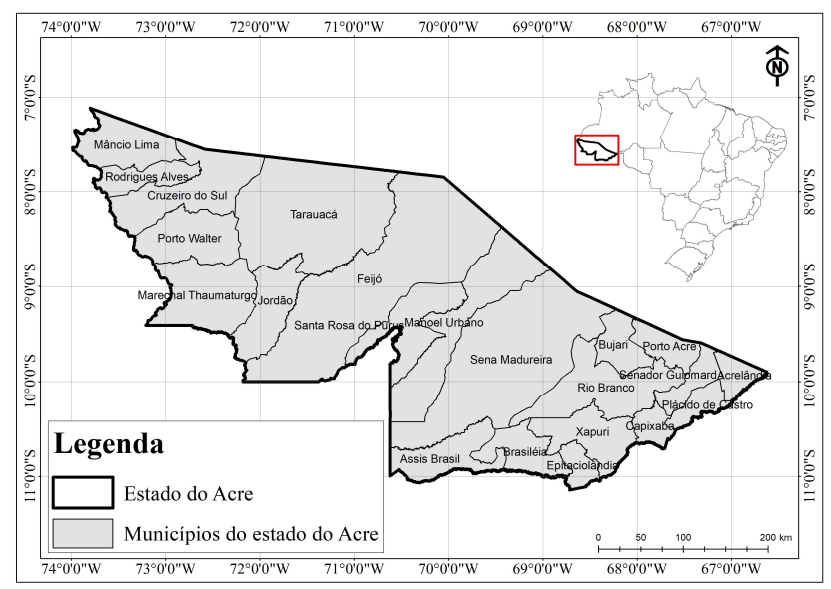

Figura 1. Localização da área de estudo envolvendo o estado do Acre e seus 22 municípios. Fonte: Malha municipal digital do IBGE (Sistema de referência SIRGAS 2000 com sistema de coordenadas geográficas).

Figure 1. Location of the study area involving Acre and its 22 municipalities. Source: IBGE's municipal digital grid (SIRGAS 2000 reference system with a geographic coordinate system).

A época mais quente ocorre entre os meses de setembro e dezembro, com temperaturas médias que variam de $25,6^{\circ} \mathrm{C}$ a $26,3^{\circ} \mathrm{C}$. As temperaturas máximas variam de $29,7^{\circ} \mathrm{C}$ a $32,8^{\circ} \mathrm{C}$ e as mínimas de $16,1^{\circ} \mathrm{C}$ a $21,8^{\circ} \mathrm{C}$. Diferente do período mais frio que ocorre entre os meses de junho e agosto com temperaturas mínimas variando de $16,1^{\circ} \mathrm{C}$ a $18,4^{\circ} \mathrm{C}$, podendo as temperaturas menores do mês atingir valores bem mais baixos, durante o fenômeno da friagem (ACRE, 2010).

\subsection{Seleção dos municípios para o zoneamento}

Para seleção dos municípios que fizeram parte da área de estudo foram realizadas duas etapas. $\mathrm{Na}$ primeira delas foi realizada uma análise de autocorrelação espacial (item 2.2.1) com os dados de focos de calor, envolvendo os 22 municípios do estado do Acre, para obtenção da distância onde ocorre o maior grau de agrupamento. Posteriormente, na segunda etapa, buscou-se agrupar os municípios em relação a quantidade de focos de calor ocorridos em 2016, o que será aclarado no tópico Análise Hot Spot para focos de calor (item 2.2.2).

2.2.1. Análise de autocorrelação espacial para determinação da distância onde ocorreu o agrupamento mais pronunciado

A ideia básica da análise de autocorrelação é que ela mede o quanto um valor observado de um atributo na região é independente dos valores desta mesma variável na localização vizinha e estima a magnitude entre as áreas, ou seja, é uma análise que mede o coeficiente de acordo com as similaridades de determinado atributo (SILVIA et al., 2004).

A análise de autocorrelação espacial foi realizada utilizando o arquivo vetorial dos municípios do Acre e, como atributo, foi utilizado a quantidade de focos de calor para o ano de 2016, em cada município. Os limites municipais são oriundos da Malha Municipal Digital do IBGE, atualização de 2015, com escala de 1:250.000. O arquivo vetorial de focos de calor foi obtido por meio do sítio eletrônico do Programa de Monitoramento de Queimadas do INPE (Instituto Nacional de Pesquisas Espaciais).

Esta análise definiu a distância máxima onde o agrupamento, para determinado atributo, foi mais pronunciado com base em valores estatísticos $z$-score. Para obtenção dessa distância foi utilizada a ferramenta Incremental Spatial Autocorrelation, do ArcGis 10.5. O resultado da distância (metros) onde ocorreu o agrupamento mais pronunciado foi utilizado na análise Hot Spot. Essa distância definiu o bandwidth (largura de banda) no agrupamento Hot Spot.

Essas distâncias onde ocorrem os pontos máximos de agrupamentos são apropriadas para serem utilizadas em ferramentas e trabalhos que necessitam de parâmetros de distância, raio ou largura de bandas. Fato esse verificado nos trabalhos de Ogneva-Himmelberger et al. (2015), Tan e Li (2014) e Maingi et al. (2012).

\subsubsection{Análise Hot Spot de agrupamento para focos de calor no estado do Acre}

Segundo Rocha; Henriques (2014), o termo Hot Spot é definido como a concentração de pontos quentes, para determinada variável. Dessa forma, para definição dos municípios que estavam na região onde ocorreu o agrupamento mais pronunciado para focos de calor foi realizada a análise de agrupamento espacial Hot Spot Analysis.

Esta análise espacial mapeou e indicou, estatisticamente, regiões com alto e baixo nível de significância para determinado atributo, neste caso focos de calor. Os municípios selecionados para este estudo foram aqueles que apresentaram probabilidade maior ou igual a $95 \%$, de pertencerem a uma região Hot Spot de focos de calor em 2016.

2.3. Variáveis preditoras que foram utilizadas no zoneamento

2.3.1. Altitude (modelo digital de elevação)

A altitude representa uma variável ambiental que influencia o risco de incêndio devido a sua relação com a umidade relativa do ar. Desse modo a altitude tem grande 
influência no risco de incêndios, onde áreas de menor altitude têm maior probabilidade de sofrer incêndios devido atingir temperaturas mais elevadas (RIBEIRO et al., 2008).

Após os downloads dos modelos digitais de elevação (MDE) (ao todo 13 cenas) foi realizado o mosaico desses arquivos, então foi utilizada o Mosaic To New Raster, do ArcGis 10.5. Os MDE foram disponibilizados pela NASA (EarthData), por meio do projeto ASTER/GDEM (Global Digital Elevation Map Announcement), com resolução espacial de 30 metros. Este arquivo único foi posteriormente recortado conforme limites da área de estudo. É importante ressaltar que este limite veio da seleção dos municípios anteriormente citados (item 2.2.2).

$\mathrm{O}$ mosaico para a variável altitude $(\mathrm{m})$ teve seus pixels agrupados e classificados em classes de riscos (TORRES et al., 2017; RIBEIRO et al., 2008), conforme pode ser visualizado na Tabela 1.

Tabela 1. Classes de riscos atribuídas segundo as amplitudes de altitudes (m) encontradas para a área de estudo.

Table 1. Risk classes assigned according to the altitudes (m) amplitudes found for the study area.

\begin{tabular}{|c|c|c|}
\hline Classes (m) & Risco & Peso \\
\hline 0 a $100 \mathrm{~m}$ & Extremo & 5 \\
\hline 100,1 a $200 \mathrm{~m}$ & Muito alto & 4 \\
\hline 200,1 a $300 \mathrm{~m}$ & Alto & 3 \\
\hline 300,1 a $400 \mathrm{~m}$ & Moderado & 2 \\
\hline 400,1 a $500 \mathrm{~m}$ & Baixo & 1 \\
\hline
\end{tabular}

Após a classificação dos pixels de altitude (m), em classes de risco, foi gerada uma imagem resultante (matriz) para a variável altitude $(\mathrm{m})$. Este procedimento se repetiu para as outras seis variáveis.

\subsubsection{Declividade (graus)}

A declividade do terreno influencia diretamente na propagação do fogo e na velocidade na qual as chamas se alastram, já que o fogo de morro acima se espalha mais facilmente e é muito difícil de ser combatido (RIBEIRO et al., 2008). Para obtenção da variável declividade (graus) foi utilizado o arquivo de altitude, por meio da ferramenta Slope (Spatial Analyst). Essa ferramenta converte os valores dos pixels de altitude (m) para declividade (graus). A imagem declividade (graus), para a área de estudo, teve seus pixels agrupados e classificados em classes de riscos (TORRES et al., 2017; RIBEIRO et al., 2008), conforme pode ser visualizado na Tabela 2.

Tabela 2. Classes de riscos atribuídas segundo as amplitudes de declividades (graus) encontradas para a área de estudo.

Table 2. Risk classes assigned according to the amplitudes of slopes (degrees), found for the study area.

\begin{tabular}{|c|c|c|}
\hline Classes & Risco & Peso \\
\hline 0 a $5^{\circ}$ & Baixo & 1 \\
\hline 5,1 a $10^{\circ}$ & Moderado & 2 \\
\hline 10,1 a $20^{\circ}$ & Alto & 3 \\
\hline 20,1 a $30^{\circ}$ & Muito alto & 4 \\
\hline$>30,1^{\circ}$ & Extremo & 5 \\
\hline
\end{tabular}

2.3.3. Orientação das encostas ou exposição das vertentes (aspecto)

A variável orientação das encostas ou exposição das vertentes está diretamente relacionada com a posição das vertentes, principalmente as que estão voltadas para o norte, ou seja, devido às condições de iluminação pelo sol, a orientação influencia na umidade e tipo do material combustível, onde às faces mais ensolaradas perdem umidade mais rapidamente facilitando o início e a propagação do fogo (RIBEIRO et al., 2008).

Para obtenção da orientação das encostas foi utilizado a imagem altitude (m), por meio do Aspect, do ArcGis 10.5. O resultado foi a imagem de altitude $(\mathrm{m})$ convertida para valores de orientação de encostas. A imagem orientação das encostas, para a área de estudo, teve seus pixels agrupados e classificados em classes de riscos (TORRES et al., 2017; RIBEIRO et al., 2008), conforme pode ser visualizado na Tabela 3.

Tabela 3. Classes de riscos atribuídas segundo as amplitudes de orientações de encostas, encontradas para a área de estudo.

Table 3. Classes of risks attributed according to the amplitudes of slope orientations, found for the study area.

\begin{tabular}{llc}
\multicolumn{1}{c}{ Classes (graus) } & \multicolumn{1}{c}{ Risco } & Peso \\
\hline 0 a $45^{\circ}$ e 315,1 a $360^{\circ}$ & Extremo & 5 \\
45,1 a $90^{\circ}$ e 270,1 a $315^{\circ}$ & Muito alto & 4 \\
90,1 a $135^{\circ}$ e 225,1 a $270^{\circ}$ & Alto & 3 \\
135,1 a $157,5^{\circ}$ e 202,51 a $225^{\circ}$ & Moderado & 2 \\
157,51 a $202,5^{\circ}$ & Baixo & 1 \\
\hline
\end{tabular}

\subsubsection{Rede viária (estradas)}

O sistema viário é composto por estradas e rodovias, possibilitando assim o trafego de veículos entre as cidades, facilitando a conexão entre regiões. Em contrapartida, podem também ser fator desencadeante de risco proeminente de incêndios florestais, devido a rotatividade de pessoas que passam por essas estradas e devem ser consideradas quando se realiza uma análise de zoneamento de riscos de fogo (RIBEIRO et al., 2008).

$\mathrm{O}$ arquivo vetorial das redes viárias, oriundo do Acre (2006), foi submetido à análise da distância euclidiana, por meio da ferramenta Euclidean Distance. Esse método permitiu obter e classificar os valores das distâncias euclidianas das estradas (redes viárias). Para a classificação das distâncias euclidianas das redes viárias, encontradas para a área de estudo, foram atribuídos pesos, conforme podem ser visualizados na Tabela 4.

Tabela 4. Classes de riscos atribuídas às amplitudes de distância euclidiana das redes viárias encontradas para a área de estudo.

Table 4. Classes of risks attributed according to the Euclidean distance amplitudes of the road networks found for the study area.

\begin{tabular}{llc}
\hline \multicolumn{1}{c}{ Classes (metros) } & \multicolumn{1}{c}{ Risco } & Peso \\
\hline 0 a $10.000 \mathrm{~m}$ & Extremo & 5 \\
$10.000,1$ a $25.000 \mathrm{~m}$ & Muito alto & 4 \\
$25.000,1$ a $50.000 \mathrm{~m}$ & Alto & 3 \\
$50.000,1$ a $100.000 \mathrm{~m}$ & Moderado & 2 \\
$>100.000,1 \mathrm{~m}$ & Baixo & 1 \\
\hline
\end{tabular}

\subsubsection{Núcleos populacionais}

Os núcleos populacionais são regiões onde assentamentos humanos se encontram dentro de áreas florestais, constituídas de poucas casas, com concentração de pessoas próximas a esses locais, fazendo o uso da agricultura, extrativismo, pecuária como fonte subsistência. Assim, aumentando substancialmente o risco de incêndios florestais devido a utilização de fogo sem atenção e cuidado devido (SONDA, 2002). 
$\mathrm{O}$ arquivo vetorial dos núcleos populacionais, presente no Acre (2006), foi submetido a análise da distância euclidiana, por meio da ferramenta Euclidean Distance. Este arquivo é dos muitos que contemplam o Zoneamento Estratégico do Estado do Acre em 2006. Esse método permitiu obter e classificar os valores das distâncias euclidianas dos núcleos populacionais. Para a classificação das distâncias euclidianas dos núcleos populacionais, encontradas para a área de estudo, foram atribuídos pesos, conforme podem ser visualizados na Tabela 5.

Tabela 5. Classes de riscos atribuídas às amplitudes de distância euclidiana dos núcleos populacionais encontradas para a área de estudo.

Table 5. Risk classes attributed to the Euclidean distance amplitudes of the population nuclei found for the study area.

\begin{tabular}{llc}
\hline \multicolumn{1}{c}{ Classes (metros) } & \multicolumn{1}{c}{ Risco } & Peso \\
\hline 0 a 5.000 m & Extremo & 5 \\
$5.000,1$ a $15.000 \mathrm{~m}$ & Muito alto & 4 \\
$15.000,1$ a $25.000 \mathrm{~m}$ & Alto & 3 \\
$25.000,1$ a $50.000 \mathrm{~m}$ & Moderado & 2 \\
$>50.000,1 \mathrm{~m}$ & Baixo & 1 \\
\hline
\end{tabular}

\subsubsection{Zonas urbanas}

A zona urbana é o espaço ocupado por uma cidade, caracterizado pela edificação contínua e pela existência de infraestrutura urbana, em que o comportamento caótico do desenvolvimento dessas zonas urbanas dificulta substancialmente o aspecto da previsão que pretende o planejamento. As mudanças e tendências recentes das áreas urbanas no Brasil favorecem cada vez mais o aumento no número de problemas ambientais comuns, que prejudicam a base de recursos naturais, causando impactos ambientais locais e globais (FIDALDO, 2013).

$\mathrm{O}$ arquivo vetorial das zonas urbanas presente no Acre (2006) foi submetido a análise da distância euclidiana, por meio da ferramenta Euclidean Distance. Esse método permitiu obter e classificar os valores das distâncias euclidianas das zonas urbanas. Para a classificação das distâncias euclidianas das zonas urbanas, encontradas para a área de estudo, foram atribuídos pesos, conforme podem ser visualizados na Tabela 6.

Tabela 6. Classes de riscos atribuídas às amplitudes de distância euclidiana das zonas urbanas, encontradas para a área de estudo.

Table 6. Risk classes attributed according to the Euclidean distance ranges of the urban areas, found for the study area.

\begin{tabular}{llc}
\hline \multicolumn{1}{c}{ Classes (metros) } & \multicolumn{1}{c}{ Risco } & Peso \\
\hline 0 a $5.000 \mathrm{~m}$ & Extremo & 5 \\
$5.000,1$ a $15.000 \mathrm{~m}$ & Muito alto & 4 \\
$15.000,1$ a $25.000 \mathrm{~m}$ & Alto & 3 \\
$25.000,1$ a $50.000 \mathrm{~m}$ & Moderado & 2 \\
$>50.000,1 \mathrm{~m}$ & Baixo & 1 \\
\hline
\end{tabular}

\subsubsection{Uso do solo}

O conhecimento sobre o uso do solo é fundamental para que se compreenda os níveis de riscos aos quais os sistemas estão sujeitos, bem como a forma mais adequada de manejo (RIBEIRO et al., 2008). A variável uso do solo é uma das mais propensas a riscos de incêndios florestais devido ao manejo utilizado nessas áreas. Dessa forma, a classificação do risco de incêndio foi realizada atribuindo peso para os riscos (TORRES et al., 2017; RIBEIRO et al., 2008), conforme pode ser observado na Tabela 7, bem como as classes de uso do solo contidas nos dados do projeto TerraClass (ALMEIDA et al., 2016), para a área de estudo.

Tabela 7. Classes de riscos atribuídas aos usos do solo do projeto TerraClass, para a área de estudo.

Table 7. Classes of risks attributed to the land uses of the TerraClass project, for the study area.

\begin{tabular}{|c|c|c|}
\hline Classes de uso do solo & Risco & Peso \\
\hline $\begin{array}{l}\text { Área não observada, desflorestamento, } \\
\text { hidrografia e mineração }\end{array}$ & Baixo & 1 \\
\hline Floresta, vegetação secundária & Moderado & 2 \\
\hline Outros & Alto & 3 \\
\hline Regeneração com pasto & Muito alto & 4 \\
\hline $\begin{array}{l}\text { Área urbana, mosaico de ocupações, não } \\
\text { floresta, pasto limpo e pasto sujo }\end{array}$ & Extremo & 5 \\
\hline
\end{tabular}

Após inserir o peso de cada uso do solo, conforme Tabela 7, o arquivo de uso do solo foi convertido para o formato raster, por meio do Polygon to Raster. Como resultado foi obtido uma matriz de uso do solo com peso de 1 a 5 , perfazendo assim a sétima e última variável do zoneamento.

2.4. Elaboração e classificação do zoneamento de riscos de incêndios florestais

As variáveis altitude, declividade, orientação de encostas, rede viária, núcleos populacionais, zonas urbanas e uso do solo foram constituídas por uma somatória, onde todas as variáveis receberam o mesmo peso. O risco final de incêndios florestais foi calculado utilizando a equação 1 abaixo.

$$
\text { Risco }=\mathrm{AL}+\mathrm{DE}+\mathrm{OE}+\mathrm{RV}+\mathrm{NP}+\mathrm{ZU}+\mathrm{US} \text { (Equação 1) }
$$

em que: AL: altitude; DE: declividade; OE: orientação de encostas; RV: rede viária; NP: núcleos populacionais; ZU: zonas urbanas; US: uso do solo.

Conforme Equação 1 supracitada, o zoneamento de riscos de incêndios florestais, para a área de estudo, traduziu a influência conjunta das sete variáveis analisadas, conforme preconizou Ribeiro et al. (2008). O resultado final do zoneamento foi uma imagem (matriz) com valores de pixels variando de sete a 35 . Vale ressaltar que esse zoneamento trabalhou com sete variáveis, dessa forma se um pixel tiver peso cinco em todas as sete variáveis, o seu resultado final será 35, para aquele pixel em questão. Da mesma forma se aplica caso outro pixel apresente peso um em todas as sete variáveis, assim sendo seu resultado final será sete.

Deste modo, a imagem obtida por meio da Equação 1 foi então classificada em classes de riscos utilizando o método quantile (SALLUN et al., 2007), com cinco classes. Os intervalos das classes de riscos foram: Risco Baixo $=7$ a 15 ; Risco Moderado = 15,1 a 17; Risco Alto = 17,1 a 19; Risco Muito Alto $=19,1$ a 21; Risco Extremo $=21,1$ a 35 .

\section{RESULTADOS}

3.1. Seleção dos municípios utilizando análise Hot Spot de agrupamento

A análise de autocorrelação espacial definiu a distância máxima onde o agrupamento foi mais pronunciado, por meio de valores estatísticos $z$-score. A distância onde ocorreu o agrupamento mais pronunciado foi de 176.445 metros, sendo seu $z$-score de 1,90. Essa distância foi então utilizada como parâmetro para realizar o agrupamento dos municípios com focos de calor considerados Hot Spot, no Acre em 2016. 
A análise de agrupamento espacial Hot Spot mapeou e indicou, estatisticamente, regiões com alto e baixo nível de significância para a quantidade de focos de calor. Como resultado, é possível notar na Figura 2 os municípios de Feijó, Manoel Urbano, Santa Rosa do Purus e Sena Madureira, que ficaram dentro desse agrupamento espacial, pois foram classificados com nível de significância superior ao adotado neste trabalho $(5 \%)$, ou seja, apresentaram probabilidade de agrupamento maior que $95 \%$, de ser um município Hot Spot para focos de calor.

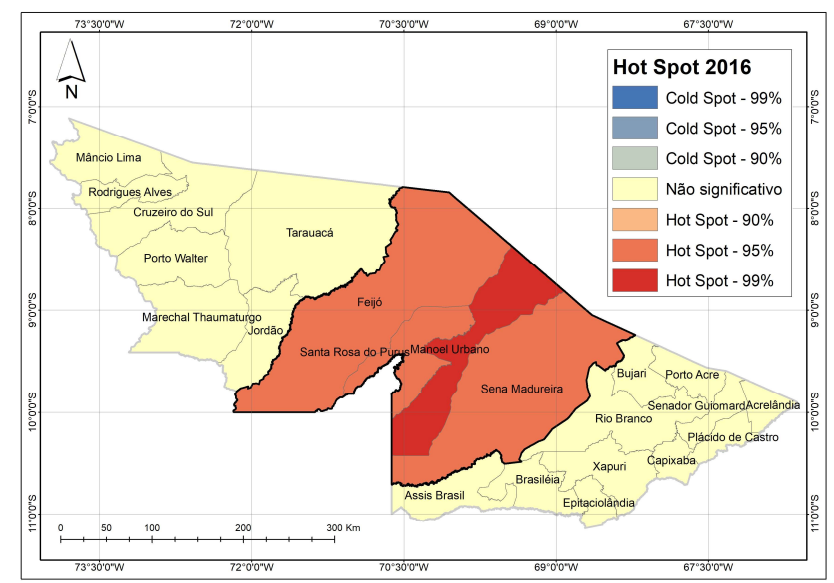

Figura 2. Resultado da análise Hot Spot de agrupamento espacial para seleção dos municípios com ocorrência de focos de calor em 2016. Fonte: Malha municipal digital do IBGE (Sistema de referência SIRGAS 2000 com sistema de coordenadas geográficas).

Figure 2. Result of the Hot Spot analysis of spatial grouping for the selection of municipalities with occurrence of hot spots in 2016. Source: IBGE's municipal digital grid (SIRGAS 2000 reference system with a geographic coordinate system).

Após a seleção dos municípios que reuniram a região de Hot Spot de focos de calor para o Acre, em 2016, a área de estudo foi definida e gerado seus limites geográficos visando a delimitação da área de estudo (Figura 2). Dessa forma, os municípios de Feijó, Manoel Urbano, Santa Rosa do Purus e Sena Madureira foram unificados para gerar esse limite geográfico. Por esta razão, todas as sete variáveis utilizadas no zoneamento obedeceram esse limite geográfico, para a realização do zoneamento de riscos de incêndios florestais.

\subsection{Variáveis preditoras utilizadas no zoneamento dos} incêndios florestais

Na Figura 3 é possível notar as sete variáveis utilizadas para o zoneamento dos riscos de incêndios florestais. Todas as variáveis foram classificadas conforme amplitudes de riscos que variaram de 1 a 5 . Nesta Figura a quadro A é a variável altitude (m), quadro B é a variável declividade (graus), quadro C é a variável orientação de encostas, quadro D é variável redes viárias (estradas), quadro $\mathrm{E}$ é a variável núcleos populacionais, quadro $\mathrm{F}$ é a variável zonas urbanas e quadro $\mathrm{G}$ é a variável uso do solo (TerraClass).

\subsubsection{Altitude (m)}

De acordo com o mapa de risco para a variável altitude (m) (Figura 3, quadro A) foi possível obter a representação de cada peso em relação a área total de estudo. Constatou-se que a classe de risco Alto (peso 3, entre 200,1 a $300 \mathrm{~m}$ ) foi responsável por $68,6 \%$ da área total, seguida pela classe de risco Muito Alto (peso 4, entre 100,1 a $200 \mathrm{~m}$ ) com 22\%, e posteriormente a classe de risco Moderado (peso 2, entre 300,1 a $400 \mathrm{~m}$ ) com apenas 9,3\%.

As classes de riscos Extremo (peso 5, até $100 \mathrm{~m}$ ) e Baixo (peso 1, entre 400,1 a $500 \mathrm{~m}$ ) tiveram baixa representatividade, respectivamente $0,01 \%$ ( $79 \mathrm{ha}$ ) e $0,2 \%$ (11.934 ha). Entretanto, quando avaliamos as classes de riscos Alto (peso 3) e Muito Alto (peso 4) é possível notar que juntas representaram 90,6\% da área total, significando de extrema importância para o zoneamento.

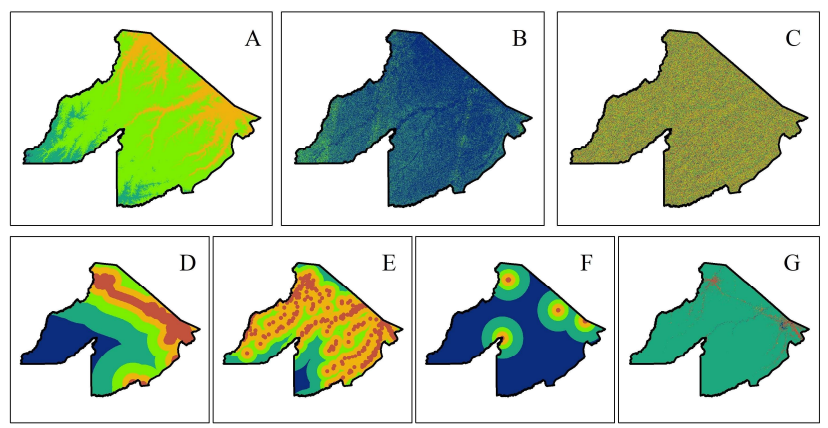

Figura 3. Variáveis utilizadas para o zoneamento de risco de incêndios florestais na região Hot Spot de focos de calor no Acre. (Sistema de referência SIRGAS 2000 com sistema de coordenadas geográficas).

Figure 3. Variables used for the risk zoning of forest fires in the Hot Spot region of hot spots in Acre. (SIRGAS 2000 reference system with a geographic coordinate system).

\subsubsection{Declividade (graus)}

De acordo com o mapa de risco para a variável declividade (graus) (Figura 3, quadro B), fica difícil a visualização e a interpretação das áreas onde os pesos ocorreram no espaço. Isso é devido ao menor contraste entre os valores para esta variável, assim sendo, a descrição a seguir ajudará no entendimento da abrangência de cada peso.

A classe de risco Baixa (peso 1 , até $5^{\circ}$ de declividade) foi a mais representativa entre todas as classes, reunindo sozinha $66,9 \%$ da área total. A classe de risco Moderado (peso 2, entre 5,1 a $10^{\circ}$ ) representou $30,3 \%$ do total. Já as classes que apresentam maiores preocupações, em relação a ocorrência de incêndios por serem mais declivosas, não tiveram expressividade relevante. Sendo a classe de risco Alto (peso 3, entre 10,1 a $20^{\circ}$ ) com apenas $2,7 \%$, classe de risco Muito Alto (peso 4 , entre 20,1 a $30^{\circ}$ ) com $0,1 \%$ e por último a classe de risco Extremo (peso 5, maior que 30,1 $1^{\circ}$ de declividade) com míseros $0,01 \%$ (915 ha).

\subsubsection{Orientação de encostas}

Da mesma forma que a declividade, o mapa de risco para a variável orientação de encostas (Figura 3, quadro C) não apresentou contraste suficiente para interpretação e identificação visual dos pesos. A classe de risco Extremo (peso 5) foi a mais representativa entre todas as classes de riscos, somando um total de $26,2 \%$ da área. A classe de risco Muito Alto (peso 4) foi a segunda em abrangência com 25,1\%, seguida da classe de risco Alto (peso 3) com 22,4\%. Essas três classes mais preocupantes, em relação ao risco que podem promover, reuniram sozinhas $73,7 \%$. Tal fato evidencia ainda mais a importância dessa variável no zoneamento. Já as classes de riscos Moderado (peso 2) e Baixo (peso 1) representaram, respectivamente, $14,2 \%$ e $12,1 \%$ da área total. 


\subsubsection{Redes viárias (estradas)}

Para a variável redes viárias (Figura 3, quadro D) a classe de risco Extremo (peso 5, até $10 \mathrm{~km}$ da rede viária) representou $14,7 \%$ do total, sendo essa área a que representa maior risco. A classe de risco Muito Alto (peso 4, entre 10,1 a $25 \mathrm{~km}$ ) representou 14,5\%. Embora em termos percentuais tenha ficado próximo da classe de risco Extremo, a distância das redes viárias dessa classe em diante, já não é fator preponderante como risco, tanto que perde força e acaba não influenciando muito no zoneamento pela distância das redes viárias. As classes de riscos Alto (peso 3, entre 25,1 a $50 \mathrm{~km}$ ), Moderado (peso 2, entre 50,1 a $100 \mathrm{~km}$ ) e Baixo (peso 1, acima de $100,1 \mathrm{~km})$ apresentaram, respectivamente, 19,8\%, 28,7\% e $22,3 \%$.

\subsubsection{Núcleos populacionais}

Ao todo foram 246 núcleos populacionais dentro da área de estudo, com as mais diversificadas denominações (seringal, colônia, fazenda, vila, etc.). De acordo com a Figura 3, quadro E é possível notar que os núcleos populacionais estão bem distribuídos na área de estudo (peso 5) e, dessa forma, exercem relevante influência sobre os riscos de incêndios. Tal fato refletiu na abrangência da classe de risco Extremo (peso 5, até $5 \mathrm{~km}$ dos núcleos populacionais), onde representou 19,9\% da área total. Se considerarmos ainda a classe de risco Muito Alto (peso 4, entre 5,1 a $15 \mathrm{~km}$ ) com 44,5\%, a soma representa 64,4\%. As outras classes de riscos Alto (peso 3, entre 15,1 a $25 \mathrm{~km}$ ), Moderado (peso 2, entre 25,1 a $50 \mathrm{~km}$ ) e Baixo (peso 1 , acima de 50,1 km), representaram, respectivamente, $18,6 \%$, $14,1 \%$ e $2,9 \%$. Essas três classes por estarem bem distantes dos núcleos populacionais acabam não influenciando diretamente no zoneamento.

\subsubsection{Zonas urbanas}

Foram apenas quatro zonas urbanas encontradas na área de estudo, sendo: Feijó, Manuel Urbano, Santa Rosa do Purus e Sena Madureira. Como pode ser visualizado na Figura 3, quadro $\mathrm{F}$, o peso 5 que corresponde a classe de risco Extremo concentrou apenas no entorno das zonas urbanas e, por isso, representou somente $0,3 \%$ da área total. Assim sendo, o efeito dessa variável no zoneamento foi bastante pontual, o que a torna importante e igualmente indispensável.

A medida que se afasta das zonas urbanas (sedes municipais) essa variável perde importância no zoneamento, mesmo que apresente considerável representatividade de abrangência. As classes de riscos Muito Alto (peso 4, entre 5,1 a $15 \mathrm{~km}$ ), Alto (peso 3, entre 15,1 a $25 \mathrm{~km}$ ), Moderado (peso 2, entre 25,1 a $50 \mathrm{~km}$ ) e Baixo (peso 1, acima de 50,1 km) apresentaram, respectivamente, $2 \%, 3,8 \%, 15,7 \%$ e $78,2 \%$.

\subsubsection{Uso do solo}

Conforme pode ser visualizado na Figura 3, quadro G, é possível perceber que a classe de risco Extremo (peso 5, área urbana, mosaico de ocupações, não floresta, pasto limpo e pasto sujo) se concentrou no entorno das redes viárias e dos núcleos populacionais. Embora tenha apresentado apenas $3,2 \%$ da área total, essa classe exerceu forte influência no zoneamento, pois juntamente com as variáveis redes viárias e núcleos populacionais, apresentaram maiores pesos para os mesmos locais no espaço.

As classes de riscos Muito Alto (peso 4, regeneração com pasto), Alto (peso 3, outros), Moderado (peso 2, floresta e vegetação secundária) e Baixo (peso 1, área não observada, desmatamento, hidrografia e mineração) apresentaram, respectivamente, $0,3 \%, 0,1 \%, 96 \%$ e $0,4 \%$. Mesmo que tenham somado $96,8 \%$ da área total, o efeito dessa variável foi mais notado para a classe de risco Extremo.

\subsection{Zoneamento e classificação dos riscos de incêndios florestais}

$\mathrm{Na}$ Figura 4 é possível visualizar o zoneamento de riscos de incêndios florestais para a área de estudo, obtido por meio da Equação 1 e as sete variáveis utilizadas neste trabalho. Bem como é possível perceber o resultado deste zoneamento classificado, pelo método quantile.

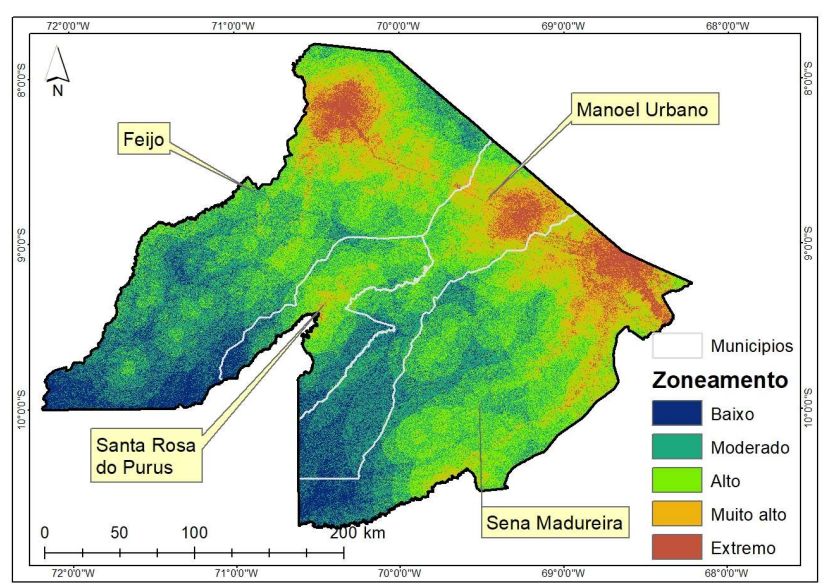

Figura 4. Mapa do zoneamento das classes de riscos de incêndios florestais, para a área de estudo. (Sistema de referência SIRGAS 2000 com sistema de coordenadas geográficas).

Figure 4. Zoning map of forest fire risk classes for the study area. (SIRGAS 2000 reference system with a geographic coordinate system).

Conforme pode ser visualizado no zoneamento da Figura 4, este foi o resultado para a região Hot Spot de focos de calor em 2016. As cores quentes significaram as regiões com risco Extremo, portanto, preocupam mais em relação aos incêndios florestais, por outro lado, as cores mais frias indicaram regiões menos preocupantes sobre incêndios florestais. Vale ressaltar que este zoneamento traduziu a combinação conjunta de sete variáveis preditoras e, por isso, todas tiveram sua importância no resultado final.

$\mathrm{O}$ resumo que quantificou os riscos de incêndios para o zoneamento em questão pode ser visualizado na Figura 5. Nesta Figura foi possível perceber que os níveis de riscos de incêndios florestais, considerados no zoneamento, apresentaram valores percentuais parecidos para algumas classes de risco. Entre essas classes destacam-se as de riscos Alto (24\%), Moderado (25,5\%) e Baixo (23,9\%). Por outro lado, os riscos mais preocupantes tiveram porcentagem modestas, em relação as outras classes de risco, sendo risco Muito Alto com $14,1 \%$ da área total e risco Extremo com apenas $12,5 \%$ da área.

Embora o risco Extremo tenha apresentado abrangência de apenas $12,5 \%$, essa porcentagem não soaria o alerta caso toda essa representatividade não estivesse agrupada, como pôde ser verificada na Figura 4 . Se esse percentual $(12,5 \%)$ estivesse distribuído de forma aleatória na área de estudo, não apresentaria riscos tão elevados, porém juntos, da forma que ocorreram, se torna uma classe extremamente preocupante para as regiões mapeadas, pois eleva significativamente o risco de incêndios florestais, bem como suas consequências. 


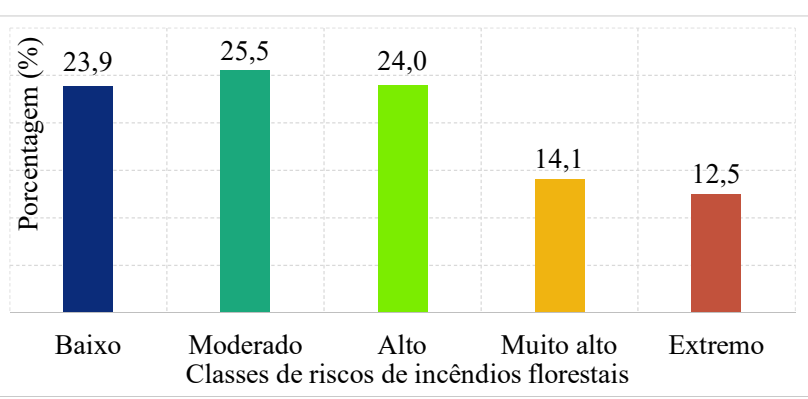

Figura 5. Resumo da representatividade, em porcentagem, para os riscos de incêndios florestais adotados neste trabalho.

Figure 5. Summary of representativeness, in percentage, for the risks of forest fires adopted in this work.

3.4. Comparação visual e espacial entre as classes de riscos de incêndios do zoneamento e os focos de calor ocorridos na área de estudo

A comparação visual da relação espacial entre as classes de risco de incêndios florestais e os focos de calor ocorridos na área de estudo, em 2016, pode ser visualizada na Figura 6.

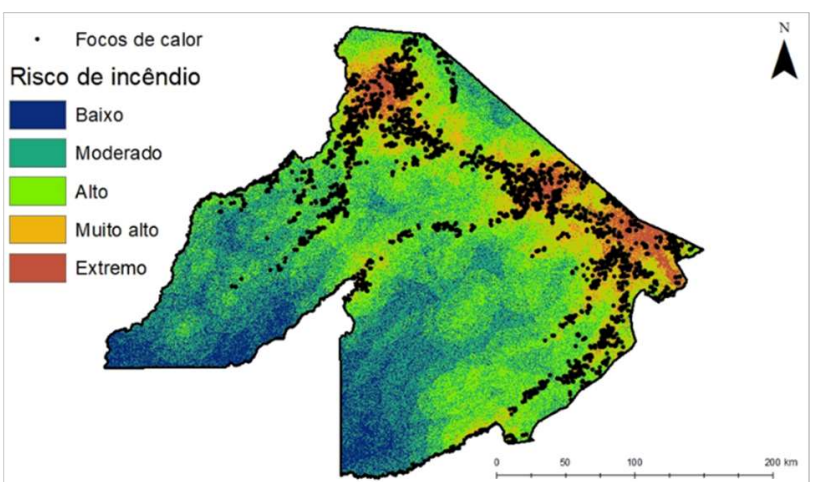

Figura 6. Classes de riscos de incêndios florestais do zoneamento intersectadas espacialmente com os 2.419 focos de calor ocorridos na área de estudo, em 2016.

Figure 6 . Risk classes of zoning forest fires interspersed spatially with the 2,419 hot spots occurring in the study area in 2016 .

Conforme visto na Figura 6, os focos de calor ocorridos na área de estudo coincidiram, visualmente em sua maioria, com as classes de riscos de incêndios mais preocupantes (Extremo e Muito alto). Tal fato evidencia que as variáveis preditoras utilizadas traduziram e conseguiram, conjuntamente, zonear os riscos de incêndios para a área de estudo. Vale ressaltar que os focos de calor não foram utilizados como variável do zoneamento, e sim apenas para a escolha da região Hot Spot de focos de calor. $\mathrm{O}$ que permite dizer que o zoneamento se mostrou coerente aos acontecimentos geográficos dos focos de calor.

Para quantificar a coincidência espacial dos focos de calor com as classes de riscos de incêndios florestais do zoneamento foi elaborada a Tabela 8. Os 2.419 focos de calor que ocorreram na área de estudo representaram 34,6\% dos focos ocorridos no estado do Acre em 2016 (6.987 focos). Do total de focos ocorridos na área de estudo (2.419), 8,8\% (213 focos) deles coincidiram espacialmente com a classe de risco Extremo. Se somarmos com os focos de calor que coincidiram com a classe de risco Muito alto $(50,2 \%=1.215$ focos $)$ chegase a representatividade de 59\% (1.428 focos) dos focos de calor.

De acordo com a Tabela 8 , se considerarmos as três maiores classes de riscos de incêndios florestais do zoneamento (Alto, Muito alto e Extremo), ao todo 89,5\% (2.165 focos) dos focos de calor coincidiram geograficamente com essas três classes.

Tabela 8. Total de focos de calor ocorridos em cada classe de risco de incêndio florestal, mapeados pelo zoneamento, bem como sua porcentagem.

Table 8 . Total heat outbreaks occurring in each class of forest fire risk, mapped by zoning, as well as their percentage.

\begin{tabular}{lrrrrrr}
\hline & Baixo & Moderado & Alto & Muito alto & Extremo & Total \\
\hline Focos & 23 & 231 & 737 & 1.215 & 213 & 2.419 \\
$\%$ & $1,0 \%$ & $9,5 \%$ & $30,5 \%$ & $50,2 \%$ & $8,8 \%$ & $100 \%$ \\
\hline
\end{tabular}

\section{DISCUSSÃO}

A altitude do terreno é uma variável importantíssima e determinante em zoneamentos, pois afeta as condições climáticas locais e atua, diretamente, nas características de umidade do material combustível. Isso significa dizer que baixas elevações apresentam maiores possibilidades de ocorrer períodos mais longos de risco de incêndios, em relação a altitudes mais elevadas (OLIVEIRA et al., 2004). Embora as amplitudes dos valores encontrados para a variável altitude, na área de estudo, não tenham sido muito discrepantes como em outros trabalhos (TORRES et al., 2008; 2011; RIBEIRO et al., 2008), as classes definidas (Tabela 1) puderam diferenciar as amplitudes encontradas e, com isso, propor riscos diferenciados mesmo com amplitudes menores.

As áreas de maiores declividades são consideradas de maior suscetibilidade ao fogo devido à transferência de calor que é facilitada no sentido do aclive, aumentando a velocidade de propagação do incêndio. A declividade tem relação direta com a velocidade, e propagação dos incêndios florestais (AGUIAR et al., 2015). Embora a declividade aliada ao clima apresente grande influência na propagação e velocidade do fogo em um incêndio (RIBEIRO et al., 2008), na área de estudo essa variável não foi determinante devido à baixa representatividade das classes de riscos mais preocupantes (Alto, Muito Alto e Extremo), pois juntos somaram pouco mais de 2,8\% da área total.

A orientação de encostas indica, indiretamente, o conteúdo de umidade do material combustível devido à iluminação do sol, que influencia consequentemente na propagação dos incêndios florestais (PRUDENTE, 2010). Para Ribeiro et al., (2008), a orientação de encostas sofre grande influência da incidência dos raios solares onde às faces mais ensolaradas perderem umidade mais rapidamente facilitando o início e a propagação do fogo devido essa grande exposição a insolação. Para o hemisfério Sul, os raios solares incidem mais diretamente sobre faces voltadas para o norte, transmitindo maior quantidade de calor para essa exposição do que para as outras. A face oeste é a segunda a receber maior quantidade de energia, seguida da face leste. A face sul é a que menos recebe radiação (TORRES et al., 2014; RIBEIRO et al., 2008). Essa variável apresentou considerável influência no resultado do zoneamento, pela ampla abrangência de suas classes de riscos mais acentuados, especialmente para o risco Extremo (26,2\%) e o risco Muito alto $(25,1 \%)$, da área de estudo.

As áreas que envolvem o entorno das rodovias são consideradas mais sujeitas ao fogo devido ao constante fluxo de veículos que nelas transitam. Dessa forma, as áreas mais próximas das estradas são mais sensíveis aos riscos de incêndios florestais (AGUIAR et al., 2015). Vários autores já mencionaram que as estradas têm papel fundamental na 
ocorrência incêndios e desmatamentos de determinado local (MATTE et al., 2015; RODRIGUES-FILHO et al., 2015), pois exercem relevante protagonismo facilitador na ocorrência destes. A variável redes viárias teve forte influência no resultado do zoneamento, tal fato pode ser evidenciado na Figura 3 (quadro D), onde o peso maior (5) dessa variável coincide espacialmente com o mapeamento ilustrado na Figura 4.

Dá-se o nome de núcleos populacionais os diferentes tipos de assentamentos humanos, lugarejo, vilarejo, povoados, aldeias indígenas, etc., sendo constituída basicamente por poucas casas. É geralmente longe e afastado dos centros urbanos e se encontram dentro de áreas de floresta e com número reduzido de pessoas, geralmente constituídas por famílias. As principais fontes de subsistência é a pecuária, agricultura e o extrativismo.

Essas atividades se não desenvolvidas com cautela podem acarretar sérios risco para as áreas de florestas que ficam no entorno, principalmente quando fazem uso de fogo, aumentando substancialmente o risco de incêndios florestais devido à falta de cuidado no manuseio do mesmo (GOMES et al., 2015). Conforme visto na Figura 3 (quadro E), a área de estudo apresentou importante distribuição espacial de núcleos populacionais, o que torna esses locais de relevante interesse no monitoramento, da mesma forma que no entorno das zonas urbanas.

As zonas urbanas estão sempre em processos contínuos de desenvolvimento. Influenciado por fatores como uso e ocupação do solo urbano e conflitos socioambientais, o crescimento urbano sem planejamento provoca agressões antrópicas sobre os recursos naturais ocasionando riscos sobre áreas naturais adjacentes, devido sua proximidade a essas zonas (FIDALDO, 2013). As quatro zonas urbanas, consideradas nesta variável, estão espacialmente localizadas em áreas de risco Extremo, conforme pode ser verificado nas Figuras 3 (quadro F) e Figura 4. Tais locais combinam várias práticas de queima de resíduos o que pode dar início a incêndios, caso haja condições necessárias para tal ocorrência.

Conhecer os diferentes usos do solo de um determinado local, além de identifica-los e classifica-los qual proporciona maior risco de incêndio, é de extrema importância para o zoneamento do risco de incêndios, pois estes usos influenciam diretamente no comportamento do fogo (PRUDENTE, 2010). Vale ressaltar que este zoneamento traduziu a combinação conjunta de sete variáveis preditoras e, por isso, todas tiveram sua importância no resultado final e foram variáveis amplamente utilizadas em trabalhos do gênero como, por exemplo, Torres et al. (2017; 2014), Ribeiro et al. (2012, 2008). Todos esses autores evidenciam e destacam o potencial das ferramentas geotecnológicas, pois potencializam 0 entendimento espacial do fenômeno estudado, além de sua quantificação espacializada.

É sabido que o risco de incêndios florestais é produto dos vários fatores conhecidos que afetam o comportamento $\mathrm{e}$ ocorrência do fogo (PAZ et al., 2011), entretanto, em estudos elaborados por Torres et al. (2008; 2011), os autores identificaram que apesar do cenário evidenciado pelo zoneamento de riscos, sem o agente causador, em sua maioria antrópico, não há ocorrência de incêndio. Tal fato foi corroborado por Nogueira et al. (2002), onde enfatizaram que em qualquer área de risco (Extremo, Baixo, etc.), o evento incêndio só irá ocorrer por meio da causa ou de uma fonte inicial de calor.
Segundo Deppe et al. (2004), a sobreposição do índice de risco em áreas que denotam elevado número de focos de calor detectados permite analisar-se o comportamento desses índices de risco, frente à situação de elevada probabilidade de ocorrência de incêndio. No Acre, desde 2011 os focos de calor têm aumentado ano após ano. Vale registrar o ano de $2005 \mathrm{com}$ 9.420 focos e, mais recentemente, os anos de 2013 (3.242), 2014 (3.827), 2015 (5.512), 2016 (6.987) e 2017 (7.029).

Embora já é sabido que sem o agente causador não há incêndio (TORRES et al., 2008; 2011), trabalhos como o de Nogueira et al. (2002), ressaltam que o incêndio irá ocorrer a partir da causa ou de uma fonte inicial de calor. Neste caso do zoneamento para a região Hot Spot de focos de calor no Acre, além de áreas com classes de riscos de incêndios preocupantes (Alto, Muito alto e Extremo), há também focos de calor com bastante ocorrência $(89,5 \%)$, que merecem ser monitorados constantemente.

\section{CONCLUSÕES}

As variáveis preditoras foram capazes de traduzir conjuntamente os riscos de incêndios florestais para a área de estudo, em que se destacam, pelos resultados visuais e espaciais do zoneamento, as varáveis: redes viárias, zonas urbanas, núcleos populacionais e uso do solo, como as que tiveram maior influência no resultado final.

A análise de agrupamento Hot Spot foi de fundamental importância para dar foco ao estudo e delimitar a região onde ocorreu, estatisticamente, o agrupamento mais pronunciado de ocorrência de focos de calor no Acre, de forma que apenas os municípios mais relevantes, neste quesito, fizessem parte do escopo do trabalho.

O mapa produzido com as classes de riscos de incêndios geoespacializadas foi de grande valia como resultado final, pois poderá oportunizar valiosas informações para subsidiar o planejamento ambiental e gestão de território em diversas ações do poder público, bem como órgãos ambientais municipal e estadual.

Por fim, não menos importante, os resultados qualificados e quantificados das classes de riscos florestais foram de extrema relevância, pois mostraram, proporcionalmente, aquelas classes de riscos mais preocupantes por terem maior abrangência e, consequentemente, maior alcance na área de estudo.

\section{REFERÊNCIAS}

ACRE_SECRETARIA DE ESTADO DE MEIO AMBIENTE; PROGRAMA ESTADUAL DE ZONEAMENTO ECOLÓGICO-ECONÔMICO DO ACRE. Recursos naturais: biodiversidade e ambientes do Acre: zoneamento ecológico-econômico fase II - escala 1:250.000. Rio Branco: SEMA, 2010. 129 p.

ACRE_GOVERNO DO ESTADO. Programa Estadual de Zoneamento Ecológico-Econômico do Acre. Zoneamento ecológico-econômico do Acre fase II: documento síntese. Escala 1:250.000. Rio Branco, AC.: Secretaria de Estado de Planejamento e Desenvolvimento Econômico Sustentável, Documento síntese, mapas temáticos, mapa subsídio a gestão territorial, 2006, 354p.

AGUIAR, R. D.; SANTOS, L. F. M.; MATRICARDI, E. A. T.; BATISTA, I. X. Zoneamento de risco de incêndios florestais no Parque Nacional da Chapada dos Veadeiros Go. Enciclopédia Biosfera, Goiânia, v. 11 n. 21, p. 1943 1957, 2015. 
ALMEIDA, C. A.; COUTINHO, A. C.; ESQUERDO, J. C. D. M.; ADAMI, M.; VENTURIERI, A.; DINIZ, C. G.; DESSAY, N.; DURIEUX, L.; GOMES, A. R. High spatial resolution land use and land cover mapping of the Brazilian Legal Amazon in 2008 using Landsat-5/TM and MODIS data. Acta Amazonica, Manaus, v. 46, n. 3, p. 291-302, 2016. DOI: http://dx.doi.org/10.1590/18094392201505504

ALVARES, C. A.; STAPE, J. L.; SENTELHAS, P. C.; GONÇALVES, J. L. M.; SPAROVEK, G. Köppen's climate classification map for Brazil. Meteorologische Zeitschrift, Berlin, v. 22, n. 6, p. 711-728, 2013. DOI: https://dx.doi.org/10.1127/0941-2948/2013/0507

BATISTA, A. C. Detecção de incêndios florestais por satélites. Floresta, Curitiba, v. 34, n. 2, p. 237-241, 2004.

COSTA, F. de S.; AMARAL, E. F. do; BUTZKE, A. G.; NASCIMENTO, S. da S. Inventario de emissões antrópicas e sumidouros de gases de efeito estufa do estado do Acre: ano-base 2010. Rio Branco: Embrapa Acre, 2012. $144 \mathrm{p}$.

DEPPE, F.; PAULA, E. V.; MENEGHETTE, C. R.; VOSGERAU, J. Comparação de índice de risco de incêndio florestal com focos de calor no estado do paraná. Floresta, Curitiba, p. 119-126, v. 34, n. 2, 2004.

FIDALGO, E.S. Risco de incêndios na interface urbanoflorestal: reflexão conceptual. RISCOS - Associação Portuguesa de Riscos, Prevenção e Segurança. Territorium, n. 20, p. 101-114, 2013.

GOMES. I.; FERREIRA, A. C.; SILVEIRA, A. C. C.; RESENDE, F. C. Comunidades rurais (mas nem tanto) proposta de definição de critérios para diferenciação ruralurbana. Geografias, Belo Horizonte, v. 11, n. 2, p. 122137, 2015.

LETTI, C. A. L. Mapas de zoneamento de risco de incêndios florestais: uma alternativa para o planejamento e controle em Santa Catarina. Florianópolis: Curso de Formação de Soldados - Biblioteca CEBM/SC, 2012. 15 p.

MAINGI, J. K.; MUKEKA, J. M.; KYALE, D.M.; MUASYA, R.M. Spatiotemporal patterns of elephant poaching in south-eastern Kenya. Wildlife Research, Victoria, v. 39, n. $3, \quad$ p. 234-249, 2012. DOI: https://dx.doi.org/10.1071/WR11017

MATTE, A. L. L.; MULLER, S. C.; BECKER, F. G. Forest expansion or fragmentation? Discriminating forest fragments from natural forest patches through patch structure and spatial context metrics. Austral Ecology, Carlton, v. 40, n. 1, p. 21-31, 2015. DOI: https://dx.doi.org/10.1111/aec.12178

MIRANDA E. E. Quando o Amazonas corria para o Pacífico: uma história. Petrópolis: Vozes, 2007, 253 p.

NOGUEIRA, G. S.; RIBEIRO, G. A.; RIBEIRO, C. A. A. S.; SILVA, E. P. Escolha de locais para instalação de torres de detecção de incêndio com auxílio do SIG. Árvore, Viçosa, v. 26 , n. 3 , p. $363-369,2002$. DOI: http://dx.doi.org/10.1590/S0100-67622002000300012

OGNEVA-HIMMELBERGER, Y.; HUANG, L.; XIN, H. CALPUFF and CAFOs: Air pollution modeling and environmental justice analysis in the North Carolina Hog Industry. International Journal of Geo-Information, v. 4, n. 1, p. 150-171, 2015. DOI: https://dx.doi.org/10.3390/ijgi4010150

OLIVEIRA, D. D.; BATISTA, A. C.; SOARES, R. V.; GRODZKI, L.; VOSGERAU, J. Zoneamento de risco de incêndios florestais para o estado do Paraná. Floresta, Curitiba, v. 34, n. 2, p. 217-221, 2004. DOI: http://dx.doi.org/10.5380/rf.v34i2.2399

PAZ, S.; CARMEL, Y.; JAHSHAN, F.; SHOSHANY, M. Post-fire analysis of pre-fire mapping of fire-risk: a recent case study from Mt. Carmel (Israel). Forest Ecology and Management, Amsterdam, v. 262, n. 7, p. 1184-1188, 2011 DOI: https://dx.doi.org/10.1016/j.foreco.2011.06.011

PRUDENTE, T. D. Geotecnologias aplicadas ao mapeamento de risco de incêndio florestal no Parque Nacional da Chapada dos Veadeiros e área de entorno. 2010. 114f. Dissertação (Mestrado em Geografia) Universidade Federal de Uberlândia, Uberlândia, 2010.

RIBEIRO, L.; VIANA, R. S.; BEPLLER, M. Mapeamento do risco de incêndios florestais no município de novo mundo, Mato Grosso, Brasil. Cerne, Lavras, v.18, n.1, p.117-126, 2012 .

RIBEIRO, L.; KOPROSKI, L. P.; STOLLE, L.; LINGNAU, C.; SOARES, R.V.; BATISTA, A.C. Zoneamento de riscos de incêndios florestais para a fazenda experimental do Canguiri, Pinhais (PR). Floresta, Curitiba, v. 38, p. 561-572, $\quad$ n. $\quad 3, \quad 2008 . \quad$ DOI: http://dx.doi.org/10.5380/rf.v38i3.12430

ROCHA, J. HENRIQUES, C. A importância da análise espacial na reconstituição da oferta educativa em Portugal. Revista Interacções, Lisboa, v. 10, v. 28, p. 21-30, 2014. DOI: https://dx.doi.org/10.25755/int.3909

RODRIGUES-FILHO, S.; VERBURG, R.; BURSZTYN, M.; LINDOSO, D.; DEBORTOLI, N.; VILHENA, A. M. G. Election-driven weakening of deforestation control in the Brazilian Amazon. Land Use Policy, Guildford, v. 43, p. 111-118, 2015.2 DOI: https://dx.doi.org/10.1016/j.landusepol.2014.11.002

SALlUN, A. E. M.; SUGUIO, K.; SALLUN FILHO, W. Geoprocessing for Alto Rio Paraná allogroup cartography (SP, PR e MS). Revista Brasileira de Cartografia, v. 59, n. 3, p. 303-313, 2007

SILVIA, J. M.; MORAES, M. L. T.; SEBBENN, A. M. Autocorrelação espacial em população natural de Terminalia argentea Mart et Succ. no Cerrado de Selvíria, MS. Scientia florestalis, Piracicaba, n. 66, p. 94-99, 2004.

SOARES, R. V. Incêndios Florestais: Controle e Uso do Fogo. Curitiba: FUPEF, 1985. 213 p.

SONDA, C. Comunidades rurais tradicionais da área de proteção ambiental estadual de Guaratuba: caracterização socioeconômica e utilização dos recursos vegetais silvestres. 2002. 193f. Tese (Pósgraduação em Ciências Florestais) - Setor de Ciências Agrárias, Centro de Ciências Florestais e da Madeira, Universidade Federal do Paraná, Curitiba. 2002.

SOUZA, D. M. Identificação dos fatores que influenciam no comportamento do fogo em incêndios florestais. 2008. 24f. Monografia (Graduação em Engenharia Florestal) - Curso de engenharia florestal, UFRRJ, Seropédica, 2008.

TAN, S. Y.; LI, J. An exploratory spatial analysis of soil organic carbon distribution in Canadian eco-regions. The International Archives of the Photogrammetry, Remote Sensing and Spatial Information Sciences, v. 42, p. 205 212, 2014. DOI: https://dx.doi.org/10.5194/isprsarchivesXL-2-205-2014 
TETTO, A. F.; BATISTA, A. C.; SOARES, R. V. Zoneamento de risco de incêndios florestais para a Floresta Nacional de Irati, estado do Paraná, Brasil. Scientia Forestalis, Piracicaba, v. 4 0, n. 94, p. 259-265, 2012.

TORRES, F. T. P.; ROQUE, M. P. B.; LIMA, G. S.; MARTINS, S. V.; FARIA, A.L.L. Mapeamento do Risco de Incêndios Florestais Utilizando Técnicas de Geoprocessamento. Floresta e Ambiente, Seropédica, v. 24 , p. 1-10, 2017. http://dx.doi.org/10.1590/21798087.025615.

TORRES, F. T. P.; RIBEIRO, G. A.; MARTINS; S. V.; LIMA, G. S. Mapeamento da suscetibilidade a ocorrências de incêndios em vegetação na área urbana de Ubá-MG. Árvore, Viçosa, v. 38, n. 5, p. 811-817, 2014. DOI: http://dx.doi.org/10.1590/S0100-67622014000500005

TORRES, F. T. P.; RIBEIRO, G. A.; MARTINS, S. V.; LIMA, G. S. Correlações entre os elementos meteorológicos e as ocorrências de incêndios florestais na área urbana de Juiz de Fora, MG. Árvore, Viçosa, v. 35, n. $1, \quad$ p. $143-150, \quad 2011$. DOI: http://dx.doi.org/10.1590/S0100-67622011000100017

TORRES, F. T. P.; RIBEIRO, G. A.; MARTINS, S. V.; LIMA, G. S.; ROCHA, G. C.; SILVA, E. Incêndios em vegetação na área urbana de Juiz de Fora: Minas Gerais. Ubá: Geographica, consultoria, estudos e projetos ambientais LTDA, 2008. 108 p. 